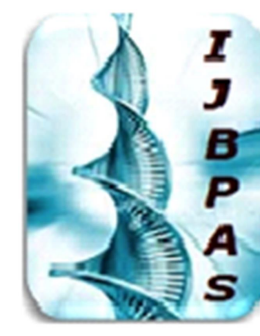

\author{
International Journal of Biology, Pharmacy \\ and Allied Seiences (IJBPAS) \\ 'A Bridge Betuen caboratory and QRendo'
}

Www.ijbas.com

\title{
BIO-APPLICATIONS OF INDUSTRY 4.0 MACHINE LEARNING HIGH-QUALITY CONTROL AND PREDICTIVE ENVIRONMENT MAINTENANCE
}

\author{
ABHIJIT MAIDAMWAR ${ }^{*}$, LOGANATHAN M.K ${ }^{2}$, DINESH MAVALURU ${ }^{3}$, \\ KIRUBAKARAN ${ }^{4}$, SURINDAR GOPALRAO WAWALE ${ }^{5}$ AND SONU KUMAR $^{6}$ \\ 1: Assistant Professor in Electronics and Telecommunication Engineering at G H Raisoni Institute of \\ Engineering and Technology, Hingana-wadi link road, MIDC, Nagpur, Maharashtra, India \\ 2: Professor in Mechanical Engineering, Assam Kaziranga University, Koraikhowa, Jorhat
}

3: Educator in Information Technology at College of Computing and Informatics, Saudi Electronic University, Riyadh, Saudi Arabia

4: Associate Professor in Information Technology, St. Joseph's Institute of Technology, OMR, Chennai, India

5: Department of Geography, Agasti Arts, Commerce and Dadasaheb Rupwate Science College, Akole, India

6: National Level Coordinator, Speak Out, Ignite, Bhumi, Chennai, Tamil Nadu-600016, India

*Corresponding Author: Abhijit Maidamwar; E Mail: abhijit.maidamwar@gmail.com

Received 22 ${ }^{\text {nd }}$ July 2021; Revised $25^{\text {th }}$ Aug. 2021; Accepted $30^{\text {th }}$ Sept. 2021; Available online $1^{\text {st }}$ Nov. 2021

https://doi.org/10.31032/IJBPAS/2021/10.11.1083

\section{ABSTRACT}

Regardless of all its already complexities in the international corporate landscape with its introduction of more modern electronic innovations, this Industry 4.0 era necessitates innovative qualitative administration methods. This research offers 5 actual examples using predicted content administration depending upon new technology, as well as novel concepts for predicting content control predicated on a comprehensive examination into current material of content control. The study's findings suggest that huge information analyses, intelligent systems, Artificial Intelligence (AI), or system building may be used to allow sophisticated innovation preventative upkeep in a variety of sectors. Proactive performance administration solutions may evolve into dynamic organisms capable of performing cause-and-effect analyses, massive information tracking and insights, and efficient ultimate judgment. Within that age approaching Industries 4.0, this paper 
presents numerous concrete consequences on both realistic construction and deployment of successful prediction content monitoring technologies. The live prediction good assurance environment, on the other hand, should be the result of an enterprise environment that encourages all parties to work together, exchange knowledge, and co-create common objectives.

Keywords: Leverage technology, qualitative enhancement, artificial intelligence, information and communication technology, Environment maintenance

\section{INTRODUCTION}

Extremely $\quad$ sophisticated management methods had been an emphasis with the emergence of connected gadgets. Significant developments are occurring within the area of operations planning as informational and telecommunication technologies (ICT) accumulates and develop with commercial domains. Because of the advancement of different IT capabilities, such as large information and AI, Service or performance monitoring techniques that were previously entirely managed by humans are getting turned into prediction services. Major technology businesses, for example, have lately created and deployed qualitative management preventative service solutions.

Preventative repair administration necessitates exchanging knowledge on output and storage stocks, as well as altering customer requirements, across interconnected associate businesses. This collaborative solution is anticipated to help meet consumer requirements by predicting demands accurately, improving operation standards, and increasing dependability [1]. Increasing the development of intelligent gadgets with identity and predicting failing characteristics will assist decrease breakdowns and operational expenses, manage stockpiles, increase repair availability, minimize the requirement of extra stocks for security, and simplify replacements time. To fulfill finished demands on proactively anticipatory management methods, Industry 4.0 must react quickly with a variety of technologies that address security, reliability, performance, and price.

Artificial intelligence (AI) is being used in a variety of sectors. Machines intelligence technologies, in particular, have expanded to both the production and services businesses to enhance facilities management production, safety, and effectiveness. Since this allows improvements within attitude, governance, cooperation, or adherence, the use of information to enhance excellence is critical. Nevertheless, according to LNS Analysis, "Quality 4.0" is not technological, rather a method in optimizing the benefit of innovative consumers [2]. As a result, service 
qualitative in the 4.0 era would be handled from a prediction instead that a preventative viewpoint, relying on electronic technologies. Whenever integrity assurance devices on a manufacturing line discover a fault, does that indicate the defect is limited to the precise things examined, or does it apply to all goods? That judgment would be tough for professionals to reach.

\section{MATERIALS AND METHODS}

Mistakes can happen at any point throughout the manufacturing processes and are induced by a variety of variables, including sloppy welding and undesirable ambient variables. Product management experts can rapidly determine if the study points towards a single faulty item or a systematic breakdown that might result in severe issues on the road. For instance, 97 percent of all defect sequences may be detected mechanically at an IBM semiconductors package factory in Canada, saving dozens of hundreds of pounds in scrap costs each year. In addition, a what-if study revealed whether regulating moisture at a crucial point in the soil's production line could enhance output integrity and yield a 160 percent payback on investment. This idea or "forecasting" service differs from "precautionary" upkeep in qualitative administration. Prospective management, on one other hand, concentrates on cost savings and failures avoidance by predicting precisely when components of a device are anticipated to develop issues, allowing substitution or repairs at the appropriate moment.

Preventative management is becoming accomplished using IoT, CPS (Digital Physical Technologies), sensors innovation, plus AI capabilities in that shape of intelligent workplaces. As industrial items were interconnected through the Internet of Things, any clever manufacturing may accomplish improvement and adaptability. Previously, workplace technology was optimal exclusively for every unit operation, with limited adaptability. Massive information from manufacturing operations is gathered, processed, and activated autonomously, leading to true proactive judgment [3]. In contrast, BOSCH, the globe's largest automobile component manufacturer, is aggressively adopting preventative management and high monitoring with the"Manufacturing Efficiency Controller," a technology scheme is built. With constant surveillance the production information \& executing advanced service works without has minimal interruption is feasible, one employee in command of management may have a beneficial influence on overall products excellence development and management with easy procedures. 
Industries 4.0 intelligent manufacture technologies can forecast RUL of hydraulic machinery and processes, averting disasters or breakdowns in locations impossible for humans to reach, and allowing for quicker reaction, reducing time induced by breakdowns. Manufacturers can also save operational costs by replacing components, as well as business potential price of lost revenue owing to interruption throughout the timeframe. As a result, qualitative administration will be reformed into proactive upkeep monitoring, with the coverage of applicable techniques expanded to include manufacturing, support, and comment governance. For tonight's businesses, there are several instances of AI, sensor systems, smart robotics, and other cognitive upkeep managers. In the chapter that follows, we look at predicted content administration techniques using example studies on grade 4.0 in industrial and services firms, who may assist establish a new digitized economic paradigm by smartening factory supplies, components, and software.

\section{Discussion on predictive maintenance}

$$
\text { Rolls-manufacturing Royce's }
$$
ecosystem has progressively been connected, while the IoT context has grown; the business has just begun employing big data to operate aircraft motors, which generates a massive quantity of data [4]. As a result of such developments, computer \& telecommunication techniques have been developed for database processing to find operating methods to reduce costs by eliminating blunders throughout the designing phase and faults during the production phase. In such an operations strategy that could identify or evaluate production conditions when issues emerge, Rolls-Royce uses large information operations in 3 key regions: development, production, and end maintenance. RollsRoyce employs nanoparticles to do preventative repair and checks, allowing its company can improve convey motor repairs and expand the usage of robotics in hazardous or unreachable areas [5]. That technology has the potential to enhance motor management procedures by speeding up inspections as part of routine servicing activities or removing the requirement to detach a powerplant from an airplane. Rolls-Royce is aggressively reducing disruptions by controlling whether airplane motors need repair using anticipatory repair.

Not just in engines research and production, but mainly in comment administration, the firm gathers and analyses information. Every little portion of a gadget, with thousands of monitors, captures and transmits within the actual 
moment to a skilled designer, permitting that architect to identify suitable responses using information analytics [6]. RollsRoyce now gathers 65,000 hours of monthly information from steam turbines, with around 100 vibrations, oxygen, thermometer, velocity, and circulation instruments mounted to 14,000 powerplants operated by 500 aircraft. Under part on its "Total Care" services, Rolls-Royce delivers true administration using information gathering following the purchase of a powerplant; this is reported to reduce delays and cancellations induced by gas generator faults, typically spend about $\$ 45$ million each week. By June 2013, the firm held 54 percent of aviation motor industry shares, with overall maintenance systems accounting for less than half of its revenues [7].

Those technologies offer additional valuation knowledge to aircraft repair staff and consumers on predicted upkeep in anticipation of potential equipment faults, allowing a new type of performance administration employing anticipatory care. Rolls-Royce can use large information processing, intelligent systems, AI, or system building to provide a foundation for sustaining high assurance with proactive repair [8]. Rolls-Royce anticipates that in the future, a corporate atmosphere will be developed one which algorithm will be able to determine its independent judgments in specific scenarios thanks to training algorithms.

Commercial processing technologies, power and construction infrastructure, consumer products and household devices, and automobile new tech are among the corporate segments that make up $\mathrm{BOSCH}$. $\mathrm{BOSCH}$ is one of the most forwardthinking profits when it comes to preventative upkeep and safety assurance. The company has a history of producing classic automobile parts and household goods. BOSCH has established Sensor product selling or consultancy companies over previous times [9]. BOSCH's operational assistance technology, which blends wirelessly connection with technology including intelligent eyewear \& monitors, ensures that assembling activity goes off with a hitch in any situation. If labor is completed correctly, a module obtains a green indicator, and the software sends a work instruction to the employee via that component, making the job procedure more convenient to manage. Through developing an intelligent method that functions responsive to circumstances, the computer or equipment also conducts preventive upkeep.

BOSCH's Industrial Management Director, a technology application that takes information from multiple resources 
in the industrial setting, codifies and integrates it, and then recreates and analyses it [10], is used for predictive management and assurance. The device displays the present status of specific equipment as well as the entire manufacturing process, allowing a service person to do operations with tiny interruption. The Management Controller checks the characteristics set in the manufacturing processes and alerts the relevant specialists as soon as circumstances surpass the danger thresholds or endanger the operation. Any person with authority may use the computational modules to make the needed maintenance on their own by picking rules from the catalog. Preventive repair managers can enhance operational performance while lowering the price of system faults and mistakes [11]. Through continually watching $\&$ recording processes \& upkeep information, the Factory Management may also enhance service reliability. BOSCH's anticipatory upkeep, which is center upon large datasets, advanced devices, AI, or platforms architecture, allows it to sustain excellent control.

Clova is a clever speaker designed by Viki, a Korean IT company, that can manage many gadgets with a simple keyboard, along with the Internet of
Things. Different AI techniques or suggested platforms enable remote management and vocal style management depending on sensing devices; text analytics, pictures, machine recognition, and conversational tasks may all be done using AI methods [12]. Clova's main significant feature is artificial intelligence, which marks a fundamental change toward a spectacular fine service. While new technological advancements continuing to add functionality, reliable knowledge would remain the greatest crucial instrument for providing such solutions. Clova would have constantly track such genuine large statistics to give consumers much better comfortable operations because Clova applications frequently use temperature and geolocation to deliver insights. Clova uses large information research, sensor technologies, AI, or system architecture to ensure high assurance with predictive management

An overview of more case studies may be found in Table 1. According to a survey of case studies, anticipatory performance monitoring techniques need sophisticated technology to deliver real operation on computer networks via a channel (NIT). During the live time, NIT constantly gives correct statistics for reliability monitoring. With obtaining elements exactly before the moment during manufacturing, the just-in- 
time (JIT) technology aims to enhance performance and reduce wastage. Using intelligent detectors and gadgets, NIT collects the important qualitative statistics and statistics in the actual moment on malware networks.

Table 1: Manufacturing Details

\begin{tabular}{|c|c|c|c|}
\hline & Hyundai & Bosch & Clova \\
\hline Purpose & $\begin{array}{c}\text { To improve the Engine } \\
\text { Maintenance }\end{array}$ & $\begin{array}{c}\text { To Provide the consumer } \\
\text { safety }\end{array}$ & $\begin{array}{c}\text { To provide the dramatic } \\
\text { real-time }\end{array}$ \\
\hline Effects & Real-time & Production Efficiency & Accurate Information \\
\hline Quality Management & Big Data & Smart Sensors & ICT \\
\hline
\end{tabular}

Hyundai Motor Company created an AI Car Diagnostics Technology which employs artificial intelligence can identify car issues depending on sound, as well as a Knocking Sensors Detecting Systems (KSDS) that analyses tremors and determines if an engine is unusual. The AI Car Diagnostics Systems makes use of AI information from over 800 different motor problems. AI software can fix a situation by employing just noise to locate the issue region and cause, and its reliability has been demonstrated in testing. Hyundai Motors relies on a quality-improvement strategy that includes anticipatory servicing and may detect issues when they occur, allowing customers to commute longer securely and pleasantly [13]. By integrating noise, vibrations, warmth, among various elements, Technology may be able to increase reliability, culminating in a solution that may be extended to any technical objects, not just vehicles. Because AI requires learning, data from a range of sounds produced in cars should be gathered $\&$ evaluated to preserve the accuracy of diagnosis [14]. As a result, intelligence, artificial intelligence, and system development are required.

\section{DISCUSSION AND EVALUATION}

There in the era of Industries 4.0, how should a live qualitative assurance environment be arranged? The quantity of businesses involved in information analytics is growing rapidly. For illustration, GE Digital offers aviation, medical, power, manufacturers, or transportation industries a framework (PaaS) named "Predix" as a service to help them effectively exploit their information. Table 2 combines the preceding instances, underlining that a preventive repair administration approach based on huge libraries and information processing, true simulators, or platforms implementation are all essential criteria for creating a live health control environment. The Internet of Things, information age, data science, data storage, 3d printers, intelligent systems, ICT, and robotics have all emerged as the result of like confluence and incorporation of revolutionary innovations, progressively 
building a society that can be fulfilled the tomorrow. Genuine information must be gathered and processed, and AI diagnostics should be done to constantly preserve production excellence [15]. As a result, large information analysis, AI, and platforms development are required. Its goals in good assurance with anticipatory service may be met simply by defining fundamental criteria \& operating procedures, as indicated in Table 2.

Table 2: Predictive Maintenance as a Quality Management Process

\begin{tabular}{|c|c|c|}
\hline Technical Prerequisites & Process of Operation & Objectives for success \\
\hline $\begin{array}{l}\text { 1. Big Data Analytics } \\
\text { 2. AI } \\
\text { 3. Platform Construction } \\
\text { 4. Smart Sensor } \\
\text { 5. Robots }\end{array}$ & $\begin{array}{l}\text { 1. Real-Time Data Analysis } \\
\text { 2. Expert Analyst } \\
\text { 3. Deep Learning } \\
\text { 4. Data Deployment } \\
\text { 5. AI }\end{array}$ & $\begin{array}{l}\text { 1. Increasing Productivity } \\
\text { 2. Min. Maintenance } \\
\text { 3. Product Quality } \\
\text { 4. Reliability Increase } \\
\text { 5. Revenue }\end{array}$ \\
\hline
\end{tabular}

In most firms, a support staff analyses information that determines the issue, then uses $\mathrm{AI}$ can determine service and replacement needs employing the key instruments and deeper training diagnosis. Nevertheless, anticipatory servicing for qualitative control, which includes sophisticated technology, may pose a threat to industry safety. In furthermore to the danger of malevolent software penetration from the outside, this same company's parallel managers could be a significant concern so because game's frailty can lead to issues like unlawful distant connectivity, inner connection connect directly via unlawful gadgets, worker mistakes, deliberate curriculum leakage, and unpermitted investment leakage.

These could be interpreted either highlighting this reality of invention can move out beyond current structures for any industrial, as well as the ideas that community would be lost if it does not adapt appropriately to Industrial 4.0 [16]. A 4 Economic Generation is a continuation of the world changes, comparable to the Three Industry Revolutions, but with a broader variety of economic and cultural disturbances, including products and services development, employment, and benefits, most of whom are unanticipated and complicated. That wide idea encompasses the digitization of resources, transforming the way companies perceive and function, as well as the emergence of new types of management and economic strategies, and using the application of technology to improve consumer and worker engagements.

That research's findings have several philosophical and operational consequences. To begin, modern electronic solutions must be used to improve efficiency \& wealth generation in the 4.0 age to allow preventative service. Second, whereas genuine deployment of large 
information insights is conceivable, regulatory assistance must be offered to specialists who may oversee or execute choices dependent upon information research. Third, operational techniques for preventive service for qualitative control must be offered with the establishment of fields ecological circumstances, techniques for evaluating research process, and predicted results. Regarding effective application using Intelligence environments containing integrated digitalization including statistics, advancements in infrastructure \& coaching need to be created [17]. Finally, in addition to electronic instruments, cryptocurrency technologies might be a key element in the development of anticipatory service and good control. Its projected benefit from preventive analytics or qualitative monitoring, depending on these recommendations, might be substantial in terms of cost savings, improved workforce productivity, agile reactions, property preservation, and knowledge exchange. While quality 4.0 refers to good digitalization, it must equally refer to the excellent technology, procedures, and individuals who influence digitalization. Since large information is being acquired within live time, quality assurance used to be conducted by information judgment. However, proof judgment has gotten increasingly essential, and the function has been highlighted. Uploading photos on Facebook, getting information on portable smartphones, and employing bank chips to pay through intelligent portable gadgets have all grown commonplace. Though this may appear to be commonplace, every activity is captured as information, and many businesses are seeking a marketing structure to make use of this information. That has evolved as a key benefit of large information. During that treatment of gathered large information and expertise production, AI is likewise a umbellar element. As a result, qualitative administration in Industry 4.0 must take the shape of a preventive upkeep managing ecology based on persons and systems, as well as the application of proof information.

That report's viewpoint is divisive since it proposes a prospective approach for qualitative administration focused on electronic information forecast servicing situations. This said investigation correlates school work because this introduces a fundamental heading for performance administration though so that forecasting throughout this same Industry 4.0 time period [18], just like Intelligence innovations it has recent times tried to penetrate our existences and software have been managed tell make inside a multitude 
of regions in which people can reply to troubles. Furthermore, every scenario evaluation in this paper has pragmatic significance since it may be employed as a great comparative instance. The following were some additional pragmatic recommendations for good improvement using anticipatory service. Predictive preservation for performance administration must be incorporated as a portion of an institutional society that encourages reworking the position of learning and rulers, developing methods for all workers to partake in ongoing advancement, and pursuing and applying genuine logfiles data analysis. Preventative upkeep and qualitative monitoring would become increasingly important in the coming for boosting efficiency and providing new benefits for all participants. Preventative service, according to Manufacturers Organization Innovation, will save $\$ 630$ billion in expenditures over the next fifteen years.

\section{CONCLUSIONS}

Our current work used research \& example studies to offer a conceptual perspective for preventive service for excellent assurance in Industries 4.0, however, this was never built on actual information. Another drawback of the research is that its hypothetical suggestion has yet to be tested. Experiential studies should be considered in upcoming studies. Furthermore, for the coming, overall viability of applications strategies for preventative upkeep for process improvement using large information analytics, AI, platforms development, supervised training, intelligent sensing, ICT, and robotics should be thoroughly investigated.

\section{REFERENCES}

[1] Lee SM, Lee D, Kim YS. The quality management ecosystem for predictive maintenance in the Industry 4.0 era. International Journal of Quality Innovation. 2019 Dec;5(1):1-1.

[2] Sezer E, Romero D, Guedea F, Macchi M, Emmanouilidis C. An industry 4.0-enabled low-cost predictive maintenance approach for SMEs. In2018 IEEE International Conference on Engineering, Technology, and Innovation (ICE/ITMC) 2018 Jun 17 (pp. 1-8). IEEE.

[3] Weber C, Hirmer P, Reimann P. A Model Management Platform for Industry 4.0-Enabling Management of Machine Learning Models in Manufacturing Environments. International Conference on Business Information Systems 2020 
Jun 8 (pp. 403-417). Springer,

Cham.

[4] Teoh YK, Gill SS, Parlikad AK. IoT and Fog Computing based Predictive Maintenance Model for Effective Asset Management in Industry 4.0 using Machine Learning. IEEE Internet of Things Journal. 2021 Jan 11.

[5] Chehri A, Jeon G. The industrial internet of things: examining how the IIoT will improve the predictive maintenance. innovation in medicine and healthcare systems, and multimedia 2019 (pp. 517-527). Springer, Singapore.

[6] Kiangala KS, Wang Z. Initiating predictive maintenance for a conveyor motor in a bottling plant using industry 4.0 concepts. The International Journal of Advanced Manufacturing Technology. 2018 Aug;97(9):3251-71.

[7] Çınar ZM, Abdussalam Nuhu A, Zeeshan Q, Korhan O, Asmael M, Safaei B. Machine learning in predictive maintenance towards sustainable smart manufacturing in industry 4.0. Sustainability. 2020 Jan;12(19):8211.

[8] Apiletti D, Barberis C, Cerquitelli T, Macii A, Macii E, Poncino M, Ventura F. iSTEP, an integrated
Self-Tuning Engine for Predictive maintenance in Industry 4.0. In2018 IEEE Intl Conf on Parallel \& Distributed Processing with Applications, Ubiquitous Computing \& Communications, Big Data \& Cloud Computing, Social Computing \& Networking, Sustainable Computing \& Communications (ISPA/ IUCC/ BDCloud/ SocialCom/ SustainCom) 2018 Dec 11 (pp. 924-931). IEEE.

[9] Sang GM, Xu L, de Vrieze P, Bai Y, Pan F. Predictive maintenance in Industry 4.0. InProceedings of the 10th International Conference on Information Systems and Technologies 2020 Jun 4 (pp. 1-11). [10] Carvalho TP, Soares FA, Vita R, Francisco RD, Basto JP, Alcalá SG. A systematic literature review of machine learning methods applied to predictive maintenance. Computers \& Industrial Engineering. 2019 Nov 1;137:106024.

[11] Paolanti M, Romeo L, Felicetti A, Mancini A, Frontoni E, Loncarski J. Machine learning approach for predictive maintenance in industry 4.0. In2018 14th IEEE/ASME International Conference on Mechatronic and Embedded Systems and Applications (MESA) 2018 Jul 2 (pp. 1-6). IEEE. 
[12] Fahle S, Prinz C, Kuhlenkötter B. Systematic review on machine learning (ML) methods for manufacturing processesIdentifying artificial intelligence (AI) methods for field application. Procedia CIRP. 2020 Jan 1;93:413-8.

[13] Ayvaz S, Alpay K. Predictive maintenance system for production lines in manufacturing: A machine learning approach using IoT data in real-time. Expert Systems with Applications. 2021 Jul 1;173:114598.

[14] Zonta T, da Costa CA, da Rosa Righi R, de Lima MJ, da Trindade ES, Li GP. Predictive maintenance in the Industry 4.0: A systematic literature review. Computers \& Industrial Engineering. 2020 Oct 6:106889.

[15] Saidy C, Xia K, Kircaliali A, Harik R, Bayoumi A. The Application of Statistical Quality Control Methods in Predictive Maintenance $\quad 4.0: \quad$ An Unconventional Use of Statistical Process Control (SPC) Charts in Health Monitoring and Predictive
Analytics. Advances in Asset Management and Condition Monitoring 2020 (pp. 1051-1061). Springer, Cham.

[16] Dalzochio J, Kunst R, Pignaton E, Binotto A, Sanyal S, Favilla J, Barbosa J. Machine learning and reasoning for predictive maintenance in Industry 4.0: Current status and challenges. Computers in Industry. 2020 Dec 1;123:103298.

[17] Saidy C, Valappil SP, Matthews RM, Bayoumi A. Development of a predictive maintenance 4.0 platform: enhancing product design and manufacturing. advances in Asset Management and Condition Monitoring 2020 (pp. 1039-1049). Springer, Cham.

[18] Calabrese M, Cimmino M, Fiume F, Manfrin M, Romeo L, Ceccacci S, Paolanti M, Toscano G, Ciandrini G, Carrotta A, Mengoni M. SOPHIA: An event-based IoT and machine learning architecture for predictive maintenance in industry 4.0. Information. 2020 Apr;11(4):202. 